\title{
Definitive radiation for early stage lung cancer: who is medically inoperable?
}

\author{
Gonzalo Varela ${ }^{1}$, Nuria M. Novoa ${ }^{2}$ \\ ${ }^{1}$ Institute for Biomedical Research of Salamanca (IBSAL), Salamanca, Spain; ${ }^{2}$ Thoracic Surgery Service, Salamanca University Hospital and School \\ of Medicine, Salamanca, Spain \\ Correspondence to: Dr. Gonzalo Varela. Thoracic Surgery Service, Salamanca University Hospital, Paseo de San Vicente 58, 37007 Salamanca, Spain. \\ Email: gvs@usal.es. \\ Provenance: This is an invited article commissioned by the Section Editor Dr. Chun-Ru Chien (Director, Department of Radiation Oncology, China \\ Medical University Hsinchu Hospital, Taiwan; Professor, Department of Radiation Oncology, China Medical University, Taiwan). \\ Comment on: Berlin E, Buckstein M, Yip R, et al. Definitive radiation for stage I lung cancer in a screened population: results from the I-ELCAP. Int J \\ Radiat Oncol Biol Phys 2019;104:122-6.
}

Submitted Aug 24, 2019. Accepted for publication Sep 05, 2019.

doi: 10.21037/atm.2019.09.49

View this article at: http://dx.doi.org/10.21037/atm.2019.09.49

In a recently published paper at the International fournal of Radiation Oncology, Biology, and Physics (1), the authors report a post-hoc analysis of a cohort of early lung cancer cases drawn from the International Early Lung Cancer Action Program database (2). The purpose of the study is to compare the characteristics and outcomes of patients diagnosed of clinical stage I non-small cell lung carcinoma (NSCLC) treated with definitive radiation therapy (RT) or surgical resection. All cases had cyto-histologically proven NSCLC. Thirty-one cases (3.6\%) were treated only by RT and $702(82.3 \%)$ by surgical resection. Despite radiated cases were older and having more comorbidities, longterm survival rate was comparable for patients treated with RT alone (15-year lung cancer-specific survival $90.0 \%)$ or surgery $(94.8 \%, \mathrm{P}=0.09)$. The authors conclude that RT appears to be a viable alternative to surgery, although results must be considered with caution due to the small numbers in the radiation cohort and the differences in median follow-up time (4.3 years in RT vs. 10.0 years in surgically treated cases).

This and other similar papers $(3,4)$ are having strong influence to indicate definitive RT in early stage NSCLC patients fit for surgical treatment. Both in the United States (5) and in Europe in elderly cases (6), an increase in the percentage of early stage NSCLC patients treated only by RT has been reported. The current evidence (7) suggests that RT for early stage NSCLC is associated with lower treatment-related mortality but surgery is superior in overall survival. For that reason, practice guidelines from major international medical societies (8) do not recommend definitive RT in such cases outside of clinical trials.

Although in some retrospective analysis of series of cases and reviews $(1,9,10)$, the authors comment that the overall survival advantage for surgery could be related to patient selection bias-healthier cases are allocated to surgery-the fact is that in most published series (11-15) RT was restricted to patients medically inoperable or refusing surgery. The definition of "medical inoperability" is lacking in some publications and rarely $(16,17)$, it is stated that patient's operability was evaluated in all cases by thoracic surgeons experienced in lung cancer surgery, as recommended (8).

In this text, we are trying to summarize currently accepted criteria to contraindicate lung resection in early stages of NSCLC.

\section{Patient refusal after accurate information}

Patient's unwillingness to accept, obviously, contraindicates surgery. Some individuals are prone to surgical anxiety and fear to surgery. We are obliged to respect patient's wills, but also to provide accurate information on the risks of each procedure. As an example, the highly cited paper by Chang et al. (17) reports a pooled analysis of two randomised 
trials of stereotactic ablative radiotherapy (SABR) versus lobectomy for stage I NSCL. The authors conclude that SABR could be an option for treating operable stage I NSCLC. In the pooled surgical arm of these studies, surgical operative mortality for lobectomy was $3.7 \%$. If such a mortality risk is offered to patients, a high rate of surgical refusal could be expected. According to the European Society of Thoracic Surgeons Database (18), current (years 2013 to 2018) surgical mortality in more than 72,000 lung cancer resections is $1.6 \%$. This rate can be even better in patients available to minimally invasive procedures (most stage I NSCLC patients). In our institution, current 30 -day mortality after VATS lobectomy for cancer is $0.42 \%$ ( 2 cases out of 479 ) and the rate of major postoperative complications 5.22 (25 cases).

\section{Patient's age}

Older age is closely related to comorbidity, disability and frailty. Therefore, a careful selection process must be done when approaching older patients. However, advanced age is not by itself a contraindication for lobectomy in stage I NSCLC. In a recently published retrospective analysis on 58 early-stage NSCLC octogenarians (19), the authors conclude that definitive lung SABR was beneficial especially for patients with a Karnofsky performance status over 75 . Such cases are expected to be fit also for lobectomy. In our series of octogenarians, 30-day mortality was $1.28 \%$ (1/78 cases). The definition of "elderly" is variable in the literature. For some authors (19) octogenarians are considered elderly cases while in other papers, patients over $65(6,20)$ are deemed elderly. In our series of surgically treated early stage lung cancer patients, median age is 66.9 ; that is, according to some authors, more than half of our surgical population could have been offered RT as definitive therapy for stage I NSCLC, while we are still waiting for conclusive evidences on the effectiveness of such a therapy.

\section{Pulmonary function}

According to the American Society of Radiation Oncology (ASTRO), standard operative risk is considered under $1.5 \%$ operative mortality (21); high operative risk is not clearly defined. More specific data regarding functional contraindications for lobectomy are provided in the American Society of Clinical Oncology (ASCO) endorsement of the ASTRO evidence-based Guideline (8). ASCO suggests high operative risk as FEV1 $<50 \%$ predicted and lung diffusing capacity (DLCO) $<50 \%$ predicted, or a combination of advanced age, impaired pulmonary function, pulmonary hypertension, and poor left ventricular function. In surgical forums, the value of predicted postoperative $\%$ FEV1 and \%DLCO (\%ppoFEV1 and \%ppoDLCO) are used instead of actual preoperative values. According to the American College of Chest Physicians evidence-based guidelines (22), if any of ppo values are within $60 \%$ and $30 \%$ predicted, stair climbing, or shuttle walking tests are the next step in the preoperative workup. In case of patient's bad performance on these (altitude $<22 \mathrm{~m}$ or shuttle walk distance $<400 \mathrm{~m}$ ), or if any ppo values are $<30 \%$, standardised cardiopulmonary exercise tests are indicated. A peak oxygen consumption $<10 \mathrm{~mL} / \mathrm{kg} / \mathrm{min}$ or $35 \%$ predicted is considered a contra-indication for lobectomy.

Anatomical segmentectomy is considered to provide functional advantages compared to lobectomy in stage IA lung cancer. In the review by Charloux and Quoix (23) the authors conclude that segmentectomy saves only a small percentage of pre-operative FEV1 with no measurable advantages for patients with poor pulmonary function. In our opinion, preoperative evaluation should be the same irrespective of the surgical technique: lobectomy or anatomical segmentectomy.

\section{Cardiac function}

Cardiac evaluation before lung surgery is described in the evidence-based guidelines from the European Respiratory Society (ERS) and the European Society of Thoracic Surgeons (ESTS) (24). The authors recommend applying the Recalibrated Cardiac Risk Index (RCRI) (25) to indicate or not additional cardiac tests. Patients with 1 or 2 RCRI score, poor functional status (suggesting decreased left ventricular function) or previous angina should be evaluated first by non-invasive cardiac testing, echocardiogram and ergometry. For patients with an estimated high risk of cardiac complications (RCRI score $=3$ ) non-invasive study is not enough despite negative results in that tests. In that subset of patients, individualized discussion at multidisciplinary team is paramount since SBRT is not free from cardiac adverse effects and mortality, especially in upper lobe and less peripheral tumours and in patients with previous history of cardiac disturbances (26).

\section{Comorbidity}

Comorbidity is highest among lung cancer patients 
compared to breast and colo-rectal cases (27). That is mainly due to the high prevalence of smoking habits and advanced age among lung cancer population. Several general comorbidity scores have been correlated with operative mortality and survival after lung resection. Of those, Charlson Comorbidity Index (CCI) is probably the most relevant. In an interesting paper by Eguchi et al. (28) CCI increase from 0 to 1 is associated to an increase of noncancer-specific and lung cancer-specific mortality; however, incidence doesn't change along with further CCI increases. In the same study, cancer-specific and noncancer-specific cumulative incidence of death are inversely correlated to ppoFEV1 and ppoDLCO values and noncancer mortality increases in patients over 75 years of age. These data are very useful in the patient information process and decision-making.

In the current absence of conclusive data from ongoing trials, we must accept that RT (more specifically SABR) can be the best treatment for some stage I NSCLC patients; but, as we have tried to show, classifying a patient as medically inoperable is not that simple as establishing functional or age cut-offs. Multi-factorial indexes based on large patient databases should be constructed as useful tools in the decision-making process. Also, patient information must be based on solid data and accurate information on the expected local rate of operative mortality and adverse events and the expected noncancer-specific mortality.

\section{Acknowledgments}

None.

\section{Footnote}

Conflicts of Interest: The authors have no conflicts of interest to declare.

Ethical Statement: The authors are accountable for all aspects of the work in ensuring that questions related to the accuracy or integrity of any part of the work are appropriately investigated and resolved.

\section{References}

1. Berlin E, Buckstein M, Yip R, et al. Definitive radiation for stage I lung cancer in a screened population: results from the I-ELCAP. Int J Radiat Oncol Biol Phys 2019;104:122-6.
2. International Early Lung Cancer Action Program Investigators, Henschke CI, Yankelevitz DF, et al. Survival of patients with stage I lung cancer detected on CT screening. N Engl J Med 2006;355:1763-71.

3. Kann BH, Verma V, Stahl JM, et al. Multi-institutional analysis of stereotactic body radiation therapy for operable early-stage non-small cell lung carcinoma. Radiother Oncol 2019;134:44-9.

4. Scotti V, Bruni A, Francolini G, et al. Stereotactic Ablative Radiotherapy as an Alternative to Lobectomy in Patients With Medically Operable Stage I NSCLC: A Retrospective, Multicenter Analysis. Clin Lung Cancer 2019;20:e53-61.

5. Haque W, Szeja S, Tann A, et al. Changes in Treatment Patterns and Overall Survival in Patients With EarlyStage Non-Small Cell Lung Cancer in the United States After the Incorporation of Stereotactic Ablative Radiation Therapy: A Population-based Analysis. Am J Clin Oncol 2018;41:259-66.

6. Detillon DDEMA, Driessen EJM, Aarts MJ, et al. Changes in treatment patterns and survival in elderly patients with stage I non-small-cell lung cancer with the introduction of stereotactic body radiotherapy and videoassisted thoracic surgery. Eur J Cancer 2018;101:30-7.

7. Cao C, Wang D, Chung C, et al. A systematic review and meta-analysis of stereotactic body radiation therapy versus surgery for patients with non-small cell lung cancer. J Thorac Cardiovasc Surg 2019;157:362-73.e8.

8. Schneider BJ, Daly ME, Kennedy EB, et al. Stereotactic Body Radiotherapy for Early-Stage Non-Small-Cell Lung Cancer: American Society of Clinical Oncology Endorsement of the American Society for Radiation Oncology Evidence-Based Guideline. J Clin Oncol 2018;36:710-9.

9. Chua GWY, Chua KLM. Which patients benefit most from stereotactic body radiotherapy or surgery in medically operable non-small cell lung cancer? An indepth look at patient characteristics on both sides of the debate. Thorac Cancer 2019. [Epub ahead of print].

10. Wen SW, Han L, Lv HL, et al. A Propensity-Matched Analysis of Outcomes of Patients with Clinical Stage I Non-Small Cell Lung Cancer Treated surgically or with stereotactic radiotherapy: A Meta-Analysis. J Invest Surg 2019;32:27-34.

11. Dreyer J, Bremer M, Henkenberens C. Comorbidity indexing for prediction of the clinical outcome after stereotactic body radiation therapy in non-small cell lung cancer. Radiat Oncol 2018;13:213. 
12. Nantavithya C, Gomez DR, Wei X, et al. Phase 2 Study of Stereotactic Body Radiation Therapy and Stereotactic Body Proton Therapy for High-Risk, Medically Inoperable, Early-Stage Non-Small Cell Lung Cancer. Int J Radiat Oncol Biol Phys 2018;101:558-63.

13. Hobbs CJ, Ko SJ, Paryani NN, et al. Stereotactic Body Radiotherapy for Medically Inoperable Stage I-II NonSmall Cell Lung Cancer: The Mayo Clinic Experience. Mayo Clin Proc Innov Qual Outcomes 2017;2:40-8.

14. Murray L, Ramasamy S, Lilley J, et al. Stereotactic Ablative Radiotherapy (SABR) in Patients with Medically Inoperable Peripheral Early Stage Lung Cancer: Outcomes for the First UK SABR Cohort.Clin Oncol (R Coll Radiol) 2016;28:4-12.

15. Kelley KD, Benninghoff DL, Stein JS, et al. Medically inoperable peripheral lung cancer treated with stereotactic body radiation therapy. Radiat Oncol 2015;10:120.

16. Schonewolf CA, Heskel M, Doucette A, et al. Five-year Long-term Outcomes of Stereotactic Body Radiation Therapy for Operable Versus Medically Inoperable Stage I Non-small-cell Lung Cancer: Analysis by Operability, Fractionation Regimen, Tumor Size, and Tumor Location. Clin Lung Cancer 2019;20:e63-71.

17. Chang JY, Senan S, Paul MA, et al. Stereotactic ablative radiotherapy versus lobectomy for operable stage I nonsmall-cell lung cancer: a pooled analysis of two randomised trials. Lancet Oncol 2015;16:630-7.

18. European Society of Thoracic surgeons. ESTS Database Annual Report, 2019. Available online: http://www.ests. org/_userfiles/pages/files/database_reports/ESTS\%20 2019\%20Silver\%20Book.pdf

19. Cassidy RJ, Patel PR, Zhang X, et al. Stereotactic Body Radiotherapy for Early-stage Non-small-cell Lung Cancer in Patients 80 Years and Older: A Multi-center Analysis. Clin Lung Cancer 2017;18:551-8.e6.

20. Maebayashi T, Ishibashi N, Aizawa T, et al. Significance

Cite this article as: Varela G, Novoa NM. Definitive radiation for early stage lung cancer: who is medically inoperable? Ann Transl Med 2019;7(Suppl 8):S361. doi: 10.21037/ atm.2019.09.49 of stereotactic body radiotherapy in older patients with early stage non-small cell lung cancer. J Geriatr Oncol 2018;9:594-9.

21. Videtic GMM, Donington J, Giuliani M, et al. Stereotactic body radiation therapy for early-stage non-small cell lung cancer: Executive Summary of an ASTRO Evidence-Based Guideline. Pract Radiat Oncol 2017;7:295-301.

22. Brunelli A, Kim AW, Berger KI, et al. Physiologic evaluation of the patient with lung cancer being considered for resectional surgery: Diagnosis and management of lung cancer, 3rd ed: American College of Chest Physicians evidence-based clinical practice guidelines. Chest 2013;143:e166S-e190S.

23. Charloux A, Quoix E. Lung segmentectomy: does it offer a real functional benefit over lobectomy? Eur Respir Rev 2017;26:170079.

24. Brunelli A, Charloux A, Bolliger CT, et al. ERS/ESTS clinical guidelines on fitness for radical therapy in lung cancer patients (surgery and chemo-radiotherapy). Eur Respir J 2009;34:17-41.

25. Brunelli A, Varela G, Salati M, et al. Recalibration of the revised cardiac risk index in lung resection candidates. Ann Thorac Surg 2010;90:199-203.

26. Reshko LB, Kalman NS, Hugo GD, et al. Cardiac radiation dose distribution, cardiac events and mortality in early-stage lung cancer treated with stereotactic body radiation therapy (SBRT). J Thorac Dis 2018;10:2346-56.

27. Wong ML, McMurry TL, Schumacher JR, et al. Comorbidity assessment in the National Cancer Database for patients with surgically resected breast, colorectal, or lung cancer (AFT-01, -02, -03). J Oncol Pract 2018;14:e631-43.

28. Eguchi T, Bains S, Lee MC, et al. Impact of increasing age on cause-specific mortality and morbidity in patients with Stage I Non-Small-Cell Lung Cancer: A competing risks analysis. J Clin Oncol 2017;35:281-90. 